\section{Cosmetic dentistry}

\section{Curiously covert veneers}

Sir, a 39-year-old male, with a history of irregular dental attendance, presented for examination at the University Dental Hospital of Manchester. His only complaint was to 'get his teeth sorted'. Medical history was unremarkable. Examination revealed 'composite-like veneers' labially on the maxillary and mandibular anterior teeth, extending on to the premolars (Fig. 1). The remaining dentition was heavily carious with gross calculus and generalised periodontitis.

The 'veneers' were not anatomically contoured and were associated with extensive gingival erythema and bleeding. The patient was unaware of what they were and why they had been placed, citing 'somewhere in Greater Manchester, six years previously' as the source. Maxillary OPG revealed moderate-tosevere horizontal bone loss in the anterior

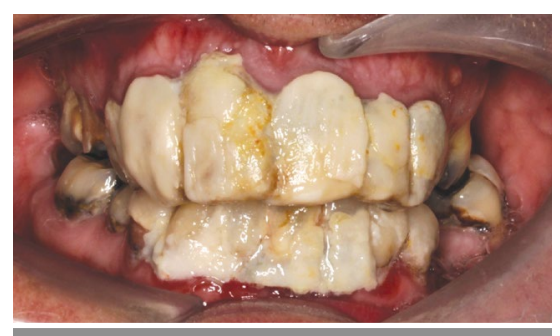

Fig. 1 Clinical photograph showing the dentition at presentation; note the DIY restorations on the anterior teeth region associated with these 'veneers' which appeared with a radiopacity similar to methacrylate/composite-resin material.

These findings were discussed with the patient, with the recommendation to remove the 'veneers' to facilitate full dental assessment and importantly to allow access to the periodontium. Despite the risks regarding mobility, spacing, change in aesthetics and the potential of hopeless prognoses of underlying teeth, the patient was well motivated.

The 'veneers' were removed with an excavator and ultrasonic scaler (Fig. 2). The ease of removal suggested the material was not adhesive; concurrent with the relative radiodensity, acrylic was suspected. Teeth $22,23,31,41$ and 43 were grade I mobile, secondary to periodontitis. The progression of periodontitis was deduced to have been accelerated by the veneers and their removal, and increased access for plaque control aimed to reduce its advancement. Regular follow-up to ensure optimal oral

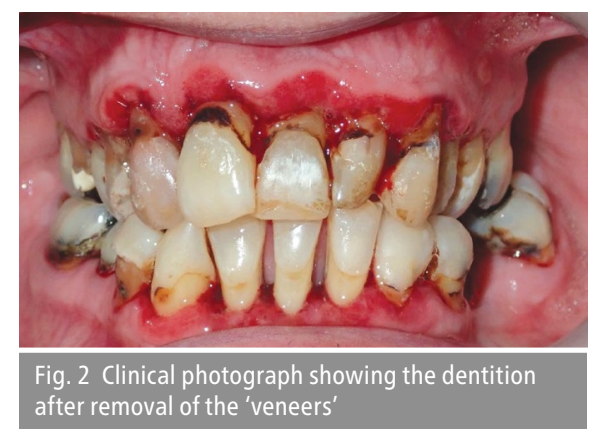

hygiene practice was strongly advocated. Arrangements were made to extract the unrestorable teeth and offer an immediate acrylic partial denture. The carious teeth were temporised until stabilisation of the dentition allows for definitive restorations.

This case highlights the implications of 'backstreet' dentistry, and although the origins of these 'veneers' are unknown, the likelihood is that they were not placed by a registered dentist. ${ }^{1}$ Similarly, atypical restorations may present due to 'do it yourself' dentistry, which has complex aetiology, including dental anxiety, access to dental care and financial stress. As access to dental care has been further limited by the current pandemic, unconventional dentistry is likely to constitute a growing challenge. ${ }^{2,3}$ In the face of such 'dentistry', it is important clinicians offer reassurance and compassion; or else, fearing embarrassment or inquisition, these patients may avoid acquiring support from the very profession that can offer it.

J. Jandu, G. R. Chase, Manchester; R. S. Burrows, Manchester and St Helens, UK

\section{References}

1. Green J. In practice: Illegal activity. Br Dent J 2016; 220: 46.

2. 'Oral health crisis' looms. Br Dent J 2020; 229: 155.

3. Missed dental appointments top 14 million. Br Dent J 2020; 229: 574.

https://doi.org/10.1038/s41415-021-2683-y

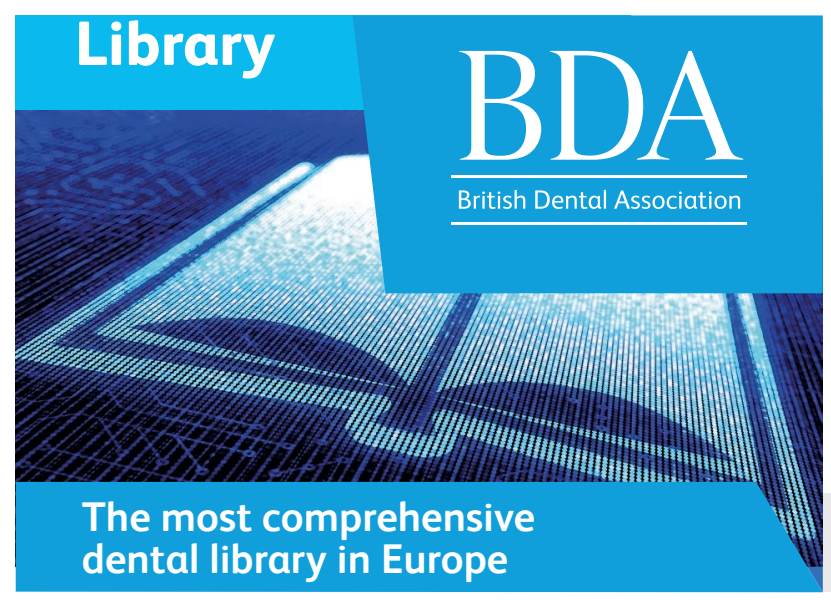

Members have tree access to a range of library services:

- eBooks: go online and access over 500 ebooks, with 30 hours of CPD, saving you time and money

- eJournals: 15 titles to read online, download or print out

- Literature searches and document supply

- Virtual topic packages available on a range of dental subjects

- Specialist revision web bundles available on key topics.

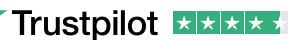

Stay connected

bda.org/library

The BDA is owned and run by its members. We are a not-for-profit organisation - all our income is reinvested for the benefit of the profession. 